\title{
A EFICIÊNCIA COMO UM CONCEITO CULTURALMENTE CONSTRUIIDO AO LONGO DA HISTÓRIA
}

\author{
Leonardo Albuquerque Marques ${ }^{1}$ \\ Fabiano Ferreira Lopes ${ }^{2}$
}

\begin{abstract}
Resumo: Com o presente trabalho, defende-se que qualquer conceito de eficiência tem um aspecto cultural significativo, não sendo um dado a priori. E, nisso, está incluída a ideia de eficiência no plano da criação e da aplicação da norma jurídica. Também é feito um apanhado de alguns conceitos de eficiência ao longo da história da humanidade para demonstrar que ele não é unívoco e para entender como ele chegou ao plano das relações interpessoais.
\end{abstract}

Palavras-Chave: Eficiência; Cultura; Nova Economia Institucional; História; Direito e Economia

\section{EFFICIENCY AS A CULTURALLY BUILT CONCEPT THROUGH HISTORY}

\begin{abstract}
With the present work, it is argued that any concept of efficiency has a significant cultural aspect, not being given a priori. In this scenery comprehends the idea of efficiency in the creation and application of legal norms. It also draws some concepts of efficiency throughout the history of mankind to demonstrate that it is not univocal and to understand how it came to the plane of interpersonal relationships.
\end{abstract}

Keywords: Efficiency; Culture; New Institutional Economics; History; Law and Economics

\section{INTRODUÇÃO}

A eficiência pode se tornar um critério de pragmaticamente operável para decisões jurídicas? Mas o que é eficiência afinal de contas? Quando alguém diz que uma decisão é eficiente, o que essa pessoa está querendo dizer com tal afirmação? Essas são perguntas que

\footnotetext{
${ }^{1}$ Doutor em Direito pela Pontifícia Universidade Católica de São Paulo. Membro associado da Associação Brasileira de Direito e Economia. Membro da ANNEP - Associação Norte e Nordeste de Professores de Processo. Professor da graduação e da pós-graduação da Universidade CEUMA. Orientador de Iniciação Científica. Advogado. E-mail: leonardoamarques@ @otmail.com. Endereço profissional: Universidade CEUMA: Rua Josué Montello, ${ }^{\circ} 1$, Renascença II, São Luís-MA CEP 65.075-120

2 Advogado e contador. Mestre em Administração e Controladoria pela Universidade Federal do Ceará, pesquisador-líder do Núcleo de Estudos em Orçamento, Finanças e Tributação da Universidade Federal do Maranhão e professor assistente na mesma Universidade. Email: fabiano@fabianolopes.com. Endereço profissional: Av. Colares Moreira, Ed. Business Center Sala 816, Renascença 2, São Luís - MA.
}

Rev. de Direito, Economia e Desenvolvimento Sustentável| e-ISSN: 2526-0057| Maranhão | v. 3 | n. 2 | p. 82 - 99 | Jul/Dez. 2017. 
podem ser melhor respondidas se estudarmos como esse conceito de eficiência foi construído e, para tanto, é necessário que estudamos o conceito de eficiência como uma experiência cultural.

No presente trabalho, serão estudados alguns dos diversos conceitos de eficiência que foram praticados na história da humanidade, de forma a evidenciar que eles nem sempre coincidem. Aqui, é defendido que a ideia eficiência tem muito mais algo de um construto cultural do que de uma forma pura assimilável pela mente humana por mera contemplação. Nesse cenário, a eficiência alocativa trazida pela economia neoclássica não comporta o único sentido possível para o termo. Não bastasse, muitas vezes a aplicação do conceito de eficiência alocativa impõe consequências de aceitação duvidosa no plano ético, como, por exemplo, a inovação tecnológica e o banimento das forças de trabalho menos qualificadas do processo produtivo (FARIA 1999, p. 237-238).

Isso colocado, é importante destacar que o termo "eficiência" comporta uma série de usos, que vão desde a eficiência de máquinas, na maximização de um output com um mínimo de input, passando pela maximização de riqueza na economia, dentre outros usos mais coloquiais, como a avaliação da conformidade do atendimento de expectativas de comportamento de uma pessoa em relação a outras.

Mas a clarividência do termo é aparente. Mesmo na mensuração de índices de eficiência energética (especialmente na termodinâmica) - onde, a princípio, o pesquisador e o aplicador estariam mais a salvo dos ruídos semântico-pragmáticos característicos das ciências sociais -, a escolha do objeto de mensuração, das variáveis de quantificação a serem trabalhadas, bem como a escolha dos instrumentos (com a respectiva calibragem) para a realização desse trabalho, são atividades que demandam cautela por parte do operador.

Enfim, determinar se um processo é, ou não, eficiente parece ser mais um juízo dotado de certa dose de arbítrio do que uma decisão tomada cartesianamente (ALEXANDER, 2008, p. 333), sem prejuízo das notórias dificuldades metodológicas de se realizarem comparações interpessoais de utilidade (HICKS, 1939, p. 699).

Em tal cenário, torna-se inevitável pensar que o uso do termo para outras áreas do conhecimento também seguisse tal linha de dedução. Assim, a avaliação da eficiência dentro de processos industriais (e aqui ingressamos no campo da economia) também se torna um processo dotado de evidente carga de arbítrio e subjetividade (ZERBE, 2001, p. 15). Aqui, a 
eficiência visa a maximização do output do trabalho por meio da administração de ativos, de maquinário e de recursos humanos.

Mesmo na área da economia industrial, eficiência, lucratividade e produtividade são termos que não andam necessariamente juntos, ainda que estejam relacionados. De uma forma simplificada: perdas de produtividade de uma atividade podem vir apesar do aumento de eficiência na sua condução, como no caso da mineração, onde os recursos mais facilmente extraíveis se esgotam primeiramente (RAA, 2010, p. 169-170).

E isso acontece mesmo se os critérios avaliação de eficiência para um dado processo tenham sido definidos de forma facilmente compreensível. Isto, e sem muitos ruídos entre seus operadores.

A aplicação do conceito de eficiência ao direito e às decisões tomadas no plano da criação e da aplicação da norma também demandam o estudo desse problema. E, como visto, mesmo um conceito de eficiência para o direito derivado daquele anteriormente praticado na termodinâmica e na economia não é um dado a priori, e pode, assim, ser sempre questionado.

Por outro lado, não adianta simplesmente ignorarmos a ideia de eficiência e a sua operabilidade no âmbito do direito. Operar o sistema jurídico (desde a legislação a até a decisão judicial) demanda recursos do contribuinte que são vertidos ao Estado pelo mecanismo da tributação. Isto é, direitos têm custos (HOLMES; SUNSTEIN, 2000). E tais custos não podem ser desperdiçados, uma vez que a capacidade de o Estado arrecadar recursos para cumprir com sua agenda é limitada. Com efeito, a capacidade de o Estado gerar receitas não é infinita. Do mesmo jeito que aumentar tributos pode aumentar as receitas do Estado, o aumento da tributação a partir de uma dada fração agregada da riqueza social pode ter o efeito de diminuir a arrecadação, e não de aumentá-la (MANKIW, 2008, p. 169-171) ${ }^{3}$. Assim, deve-se ter muito cuidado no emprego dos recursos do contribuinte nesse ponto, inclusive para que se evite um experimentalismo institucional irresponsável, pois isso implicaria em desperdício de recursos (POSNER 2009, p. 478).

\footnotetext{
${ }^{3}$ A isto se denomina "curva de Laffer". Isso quer dizer que, se a tributação for equivalente a zero por cento da riqueza, a receita estatal será, obviamente, zero. Por outro lado, se a tributação for equivalente a cem por cento da riqueza social, as pessoas não terão incentivos para produzir, o que também levará à ausência de riqueza tributável e, novamente, a receita estatal será zero. Entre esses dois percentuais, há, ainda, uma alíquota que maximizará as receitas públicas, onde um aumento ou diminuição desse percentual levará necessariamente a uma diminuição das receitas do Estado. Assim, a agenda estatal não pode ser dimensionada para além desse potencial realizável.
} 
Ainda nesse debate, recapitulemos as observações de Ivo Gico Jr. (2012, p. 28) no sentido de que toda regra que gera desperdício é injusta e que a análise das consequências possíveis de decisões relativas à alocação de direitos (com ponderação dos diagnósticos, prognoses e custos de oportunidade) é essencial para que tais decisões sejam adequadamente tomadas.

Portanto, é necessário mergulharmos no debate sobre a construção da eficiência para uma discussão de sua aplicabilidade e operabilidade para as decisões jurídicas (legislativas ou judiciais).

Inicialmente, será feito um breve estudo sobre o uso do conceito de eficiência do cenário pré-revolução industrial até os nossos dias. Isso é feito com a finalidade de demonstrar que o conceito de eficiência (especialmente no plano da ação intersubjetiva) tem muito mais um aspecto de uma construção cultural (sintética) a posteriori do que de um dado a priori, sem qualquer intuito de se esgotar o tema ${ }^{4}$.

Como método, o presente trabalho adota a revisão bibliográfica, com predominância para os referenciais teóricos da Nova Economia Institucional, especialmente com base nos trabalhos de Ostrom (2005) e North (1981; 1990), que servirão com ponto de partida para de demonstração da necessidade de conformação específica para aplicação da ideia de eficiência em processos decisórios.

\section{ORIGEM ETIMOLÓGICA DO TERMO E SEU EMPREGO ATÉ O INÍCIO DA EXPERIMENTAÇÃO CIENTÍFICA}

Até o advento método científico, o termo eficiência estava ligado à administração adequada dos recursos disponíveis - especialmente terra e trabalho - com um mínimo de desperdício, aproximando-se do conceito estático de eficiência, mas também compreendendo uma administração adequada dos riscos e contingências que poderiam decorrer da especulação - agora, aproximando-se da eficiência no seu âmbito dinâmico (HUERTA DE SOTO, 2009, p. 2-3).

\footnotetext{
${ }^{4} \mathrm{Em}$ tempo, é feito um recorte temporal no sentido de limitar o conceito estudado ao período imediatamente anterior ao advento do critério de Pareto, introduzido no começo do século XX. Embora o estudo dos critérios Pareto e Kaldor-Hicks também sejam extremamente relevantes, a densidade dos mesmos faria com que cada um dos critérios comportasse um estudo em separado, o que será feito em trabalho posterior.
}

Rev. de Direito, Economia e Desenvolvimento Sustentável| e-ISSN: 2526-0057| Maranhão | v. 3 | n. 2 | p. 82 - 99 | Jul/Dez. 2017. 
Devemos ter em mente que, até certa de trezentos anos atrás, predominava uma tradição meramente contemplativa quanto à cosmologia. Isso é, a ideia de experimentação como método de avaliação da realidade empírica estava longe de ser consenso ${ }^{5}$. O conhecimento tinha um caráter notoriamente especulativo e, ainda que alguma observação empírica tivesse lugar, a resolução de problemas estava notoriamente ligada ao uso da razão. Na verdade, a cosmologia era notoriamente fruto da reflexão e da contemplação ${ }^{6}$ (ARENDT, 2007, p. 22, ARISTÓTELES, 1984, p. 51-56).

Era raro que filosofia dedicasse maiores reflexões sobre como aumentar a produtividade do homem tanto em relação ao solo como em relação aos demais aspectos do plano prático de sua vida. No entanto, mesmo em tal período, era possível a ocorrência, de quando em quando, de inovações no estado da técnica - a exemplo da mudança do sistema de rotação dupla para a rotação tripla de colheitas (NORTH; THOMAS, 1973, p. 43-45). Também não pode ser esquecido que boa parte da tecnologia utilizada pela Europa até meados do século foram "heranças" deixadas pelas civilizações islâmicas e bizantina, dentre as quais citem-se o ensino clínico, métodos de construção naval, notas musicais, avanços na alquimia, avanços na astronomia, numerais arábicos, tecnologia bélica, dupla entrada de contabilidade, precisão geométrica etc. (ALI, 2012, p. 161).

Isto é, até então, um conceito mais próximo ao uso moderno da eficiência seria uma total ausência de sentido. Isso decorre de a eficiência, no sentido moderno do termo, estar associada ao desenvolvimento da investigação científica. E tal modalidade de investigação com teorias sustentadas pela experimentação, permitindo a "generalização" do processo de compreensão (ainda que em caráter provisório) da realidade numa escala sem precedentes não existia no cenário anterior à revolução industrial. A margem de ação cosmologicamente permitida ao homem era muito mais restrita que a atual. A velocidade das comunicações eram

\footnotetext{
${ }^{5}$ Lembremos que, na visão geocêntrica do universo, não havia uma concepção qualitativamente uniforme das possibilidades de manipulação da realidade para facilitar o processo de adaptação. As entidades do firmamento eram dotadas de dignidades diversas e inconfundíveis (REALE; ANTISERI, 2003, p. 209), baseadas num conhecimento especulativo, onde os desvios não raro eram tratados como heresias (ou como atos de bruxaria etc.) pela igreja, num cenário marcado por alguns eventos que hoje seriam repugnantes, a exemplo das inúmeras execuções por queima na fogueira. Aliás, a dissecação de cadáveres humanos ou de animais não raro era tratada como necromancia, o que faria impossível a prática da medicina e da biologia nos moldes atuais. Isso, por si só, já se constitui num desincentivo para a ocorrência de novas descobertas no campo do conhecimento.

${ }^{6}$ É importante lembrar que, desde a queda de Roma, a Europa se manteve em considerável isolamento cultural do resto do mundo, enquanto os árabes e os bizantinos experimentavam considerável progresso científico para os padrões do período que vai do século VIII ao XVI.
}

Rev. de Direito, Economia e Desenvolvimento Sustentável| e-ISSN: 2526-0057| Maranhão | v. 3 | n. 2 | p. 82 - 99 | Jul/Dez. 2017. 
as mesmas da locomoção física dos agentes comunicadores e a ideologia teocêntrica ocidental então prevalecente, de hostilização de povos não-cristãos diminuía drasticamente as possibilidades de trocas de experiência (se compararmos com os padrões atuais). Aliás, mesmo civilizações não-cristãs também adotavam essas postura de hostilização (que variava de intensidade através do tempo), a exemplo dos expurgos ocasionais de judeus e cristãos no mundo islâmico antigo, que ocorriam vez por outra (HOURANI, 2006, p. 165).

Outro fator que desincentivava as pessoas para que se engajassem na atividade inventiva consistia na ausência de proteção para o conhecimento adquirido, ainda que superados os óbices acima. Em tal cenário, mesmo a aquisição de novos conhecimentos pelos integrantes das corporações de ofício não se dava de forma sistemática. Isto é, o incremento da eficiência dos métodos, voltados para o que Hanna Arendt (2007, p. 90 et seq.) atribui à esfera do "trabalho" ou do "labor" (conforme o caso) na "vita activa" " e, portanto, ligados, a um conhecimento menos digno que o escolástico-acadêmico ${ }^{8}$ e a um plano de ação menos nobre que a política. Com efeito, esses incrementos visavam apenas a uma melhoria pontual das atividades desenvolvidas para melhor moldagem da realidade às necessidades humanas, mas tudo dentro dos limites estabelecidos pelas estruturas de incentivos então vigentes.

Dito de outra forma, falar em eficiência nesse cenário inicial era algo restrito a um uso pontual, ainda que fosse possível identificar algum sentido que expressasse algo que remetesse à prática contemporânea do termo. Afinal de contas, o uso dos recursos que o homem encontra na natureza e os seus processos de transformação, até a revolução industrial, eram notadamente artesanais, não havendo sentido nenhum falar em eficiência industrial até então.

Isto é, na época, não faria sentido nenhum falar-se em eficiência no sentido moderno do termo. Isso decorre de a eficiência, nesse sentido moderno, estar associada ao desenvolvimento

\footnotetext{
${ }^{7}$ Em tempo, é importante ressaltar que a autora tem uma postura saudosista com o mundo clássico, destacado, todavia, que historicamente as evidências apontam muito mais para a ausência de sociedades e de instituições marcadas pela ação política nos termos defendidos por ela e por Aristóteles do que pela sua presença. Neste ponto, cf. North (1981, p. 24), segundo o qual as sociedades, desde a revolução neolítica (isto é, a primeira revolução social em que o homem descobre a sua capacidade de instrumentalizar a natureza para o atendimento de suas necessidades, deixando progressivamente de ser caçador-coletor nômade, tornando-se pastor-agricultor sedentário, em cerca $10.000 \mathrm{AC}$ ) foram marcadas por um conjunto de instituições excludentes (as quais continuam bastante presentes na atualidade). Foi nesse tipo ambiente institucional que as invenções realizadas até cerca de 300 anos atrás se deram, não sendo demais lembrar que cerca de $85 \%$ da população mundial ainda vive sob o jugo de tal modalidade de instituições.

${ }^{8}$ Isoladamente, é possível encontrar escritos isolados que tratam de temas como taxas de desconto. Como exemplo, segundo. Dempsey (1948, p. 214), há um estudo de Giles (Aegidius) Lessines, um discípulo de São Tomás de Aquino, sobre uma concepção medieval das taxas de descontos entre valor presente e valor futuro.
} 
da investigação científica. E tal modalidade de investigação - com teorias sustentadas pela experimentação, permitindo a "generalização" do processo de compreensão (ainda que pela apresentação de modelos provisórios de explicação) da realidade numa escala sem precedentes - não existia no cenário pré-revolução industrial ${ }^{9}$. Foi a partir do renascimento do comércio, com a exploração das rotas para o Oriente, que começaremos a ver uma mudança nesse campo.

Mas, mesmo antes da revolução industrial, existem algumas sociedades que apresentavam maiores níveis de tolerância cultural e que poderiam ser consideradas inclusivas dentro dos padrões modernos. Um exemplo, dentre vários, é o da República Veneziana. Em tal ambiente, tivemos surtos de desenvolvimento com base em instituições inclusivas - com uma série de inovações institucionais como as sociedades em comandita, a criação de um sistema bancário, a criação do contrato de seguro, um sistema de solução de controvérsias adjudicadas por agentes independentes, dentre outros. Todavia, as instituições venezianas voltaram a ser excludentes a partir do século XIV, por ocasião do seu fechamento político e econômico, denominado "La Serrata” (ACEMOGLU; ROBINSON, 2012, p. 120-122).

Pois bem, colocado esse cenário, faremos uma análise de sua pertinência para a presente linha de raciocínio.

É importante destacar que, culturalmente, a ascensão de Veneza é um acontecimento fortuito decorrente de alguma mudança de um cenário tradicionalmente marcado por instituições excludentes para outro cenário marcado por outras que foram mais inclusivas. Não havia evidências anteriores de que essa inclusividade institucional - tanto no âmbito de mercados como no processo de participação política - poderia acontecer. De qualquer forma, esse progresso decorrente da abertura institucional foi revertido posteriormente. A partir de um momento, o processo de inclusão implodiu e Veneza voltou a ser marcada por instituições excludentes.

Não bastasse, o caráter inclusivo das instituições econômicas e políticas venezianas decorreu exatamente do desenvolvimento das esferas de ação que o pensamento aristotélicotomista jogou para um segundo plano. Mais especificamente: o labor e o trabalho. Mesmo a política assumia aqui uma relevância secundária por consistir no emprego da ação para a

\footnotetext{
${ }^{9}$ A margem de ação cosmologicamente permitida ao homem era muito mais restrita que a atual. A velocidade das comunicações eram as mesmas da locomoção física dos agentes comunicadores e a ideologia teocêntrica ocidental então prevalecente, de hostilização de povos não-cristãos, diminuía drasticamente as possibilidades de trocas de experiência (se compararmos com os padrões atuais).
}

Rev. de Direito, Economia e Desenvolvimento Sustentável| e-ISSN: 2526-0057| Maranhão | v. 3 | n. 2 | p. 82 - 99 | Jul/Dez. 2017. 
finalidade de suprir meras necessidades fundamentais da subsistência humana, em vez de almejar finalidades mais "virtuosas". Os ambientes acadêmicos e clérigos mais "dignos", por sua vez, também não contribuíram em nada para esse ciclo por se manterem distantes dessa realidade mais "mundana", pois se mantiveram dentro de seu enclausuramento contemplativo inerente à sua perspectiva filosófica. Isso leva a uma conclusão inicial de que administrar a satisfação das necessidades humanas, era um subproduto dessa vida política "de segunda", marcada por instituições formais e informais que norteavam os conflitos sociais que surgissem ao longo do tempo. Afinal de contas, em tal momento, lidar com a escassez e falar em eficiência nos processos de produção era algo inapropriado para a dignidade contemplativa das mentes acadêmicas enclausuradas em mosteiros ${ }^{10}$. Aliás, não é à toa que a usura e a ideia de preço justo - associada a uma ideia de controle eclesiástico da economia - foram os temas práticos mais abordados até a Escola de Salamanca, a qual será abordada logo abaixo.

Foi com o advento da Escola de Salamanca no Século XVI que uma abordagem prática do comportamento humano, com foco nos incentivos e nas consequências das ações tomadas, que a ideia de eficiência - ainda que de uma forma latente - no plano da ação prática começa a fazer parte de uma pauta acadêmica ostensiva (HAYEK, 1985, p. 92-93). É com a Escola de Salamanca que surge uma série de lugares comuns (que seriam futuramente incorporadas na teoria econômica) como a teoria do valor, a relação entre preços e custos, a natureza dinâmica do mercado e a impossibilidade de um equilíbrio perfeito, a ideia de taxa de desconto entre valor presente e futuro, dentre outros (HUERTA DE SOTO, 2010, p. 55-56), com notório foco para o plano empírico. E, em que pese o insucesso de tal movimento acadêmico reverter a derrocada espanhola que então estava em andamento, a Escola de Salamanca continuou a influenciar a filosofia da moral e do direito por mais um século e pensadores da economia ortodoxa como Walras e Say, além dos pensadores da Escola Austríaca (GRICEHUTCHINSON, 1952, p. 59-78).

Enfim, em situações histórica e geograficamente isoladas, conseguimos perceber o surgimento de instituições que permitiram o desenvolvimento econômico e político de sociedades, num cenário sem precedentes na história. E, até o surgimento da Escola de Salamanca (sobre a qual será aprofundado mais à frente), isso ocorreu justamente em ambientes

\footnotetext{
${ }^{10}$ É importante destacar que, até a invenção da prensa de Gutemberg, toda a informação contida no mundo só era reproduzida a um alto custo por meio do trabalho de copistas, que se comunicavam por meio de uma língua morta, o latim.
} 
marginalizados de estudo, os quais constituíram o âmbito de operação do conceito de eficiência da antiguidade clássica - isto é, no sentido de se extrair o máximo de algo, empregando-se o mínimo de insumos.

\section{A REVOLUÇÃO DE COPÉRNICO, A REVOLUÇÃO INDUSTRIAL E A MÁQUINA} A VAPOR: MESMO A EFICIÊNCIA APLICADA A MÁQUINAS DEMANDA A ADAPTAÇÃO DE MODELOS GERAIS ÀS ESPECIFICIADES DOS CENÁRIOS DE APLICAÇÃO

Como é de conhecimento comum, Nicolau Copérnico foi o primeiro a formular uma teoria formal do heliocentrismo, onde a Terra deixa de ser o centro do firmamento e passa a ocupar apenas a órbita do sol. Posteriormente, Galileu Galilei trouxe a sua comprovação empírica por meio da invenção do telescópio. E, mesmo assim, a difusão de tal pensamento ao público em geral só se tornou possível a partir do ano de 1.758, quando as obras que defendiam a teoria heliocêntrica deixaram de ser proibidas pelo Santo Ofício.

Após a adoção efetiva do heliocentrismo no contínuo da ideia de cosmologia partilhada pela sociedade como um todo, a realidade passa a ser mediatizada por um conjunto de leis matemáticas, cuja descoberta se torna possível a partir da experimentação (ARENDT, 2007, p. 286-287). Nesse cenário, temos ainda a ocorrência das circunavegações, onde "o homem tomou plena posse de sua morada mortal", tornando viável a instrumentalização da representação do espaço terrestre por meio de uma linguagem racional e matemática (ARENDT, 2007, p. 261 263).

A partir daí, terra, firmamento e tudo o que está entre um e outro passam a ser abordados de forma unificada e homogênea, normalmente com a finalidade de aumentar a capacidade de controle de contingências. Esse controle é instrumentalizado pela linguagem para comunicar, assimilar e compreender de que forma é possível plastificar os domínios do mundo sensível.

Nesse cenário, é importante adicionar uma invenção que foi fundamental para consolidar essa capacidade de instrumentalização do ambiente em que o ser humano se encontra inserido: a máquina a vapor de James Watt.

Rev. de Direito, Economia e Desenvolvimento Sustentável| e-ISSN: 2526-0057| Maranhão | v. 3 | n. 2 | p. 82 - 99 | Jul/Dez. 2017. 
Essa inserção da máquina de James Watt no desenvolvimento da presente linha de raciocínio não se faz à toa ${ }^{11}$. Três aspectos relacionados a esse ponto são essenciais aqui:

1. O conceito moderno de eficiência está essencialmente relacionado à máquina a vapor. Com a descoberta da primeira lei da termodinâmica (lei da conservação da energia), a formulação de métodos e processos que consigam gerar o máximo de trabalho (seja para gerar movimento, seja para gerar elevação) com um consumo mínimo de energia (mais especificamente: de calor), torna-se algo a ser sempre perseguido. Isto é, quando o processo consegue maximizar os retornos com um mínimo de input, diz-se que ele está sendo feito de forma eficiente (HUERTA DE SOTO, 2009, p. 4).

Desta forma, o conceito de eficiência (estática) como obtenção de um máximo de resultado sofre uma "modernização" e ganha uma nova dimensão de aplicação. A eficiência passa, agora, a integrar os processos industriais, não mais se limitando aos processos artesanais pré-modernos;

2. Ainda no século XIX (não muito depois da invenção da máquina a vapor), Carnot publica, em 1824, trabalho intitulado "Réflections sur le Puissance Motrice du Feu", onde procura compreender as sucessivas falhas na criação de um moto-perpétuo. Surge, aqui, a segunda lei da termodinâmica, a lei da entropia, a qual, em síntese, dispõe que os processos de conversão de energia em sistemas fechados aumentam o seu nível de entropia, não sendo possível o retorno ao nível de entropia anterior. É importante destacar aqui que a aplicabilidade da lei da entropia não se restringe aos processos mecânicos, mas a qualquer processo físicoquímico de conversão de energia (BUMSTEAD, 1921, p. 297) incluída a respiração celular (a qual, aliás, não deixa de ser um processo de quebra molecular, que libera calor e os compostos químicos daí resultantes);

3. É a partir daí que teremos a base do conceito moderno de eficiência no âmbito da ação prática, especialmente na economia. Por enquanto, importa vermos como se deu a transposição do conceito de eficiência das máquinas industriais para as relações interpessoais na indústria e, daí, para os demais âmbitos da cadeia de produção ${ }^{12}$.

\footnotetext{
${ }^{11}$ Outras invenções, inventores e teorias - como a mecânica de Newton -poderiam ter lugar aqui, mas o escopo da exposição feita neste tópico deve estar adstrito à proposta do presente trabalho, que é estudar como o conceito de eficiência ingressa na ação prática do homem.

${ }^{12}$ Por cadeia de produção, deve ser entendida toda a cadeia desde a captação dos insumos mais primários até a distribuição para o consumidor final, bem como a formatação das regras e instituições que regem as diversas relações dos diversos agentes que atuam nesse processo (empregados, proprietários de indústrias, consumidores, produtores de recursos primários, transportadores etc).
}

Rev. de Direito, Economia e Desenvolvimento Sustentável| e-ISSN: 2526-0057| Maranhão | v. 3 | n. 2 | p. 82 - 99 | Jul/Dez. 2017. 
De qualquer forma, é importante ressaltar que essa aplicação "cartesiana" do conceito de eficiência a máquinas também não passa imune a críticas. Elinor Ostrom (2005, p. 117), discorrendo sobre as limitações da aplicação da teoria da escolha racional, especialmente em cenário de escolhas que envolvem bens não negociados em mercado, destaca que, mesmo o caráter universal das leis da física não elimina a necessidade de formulação específica de modelos, de matrizes de aplicação e de detalhamentos específicos para a fabricação de máquinas e motores. Ainda segundo a autora, para prever a quantidade de energia usada por veículos, o seu tempo de serviço, a resistência a impactos, dentre outras variáveis importantes, um engenheiro necessita saber de fatos específicos sobre a situação (quantidade de tráfego, tipo de via trafegada etc.), além do tipo de motor envolvido (composição, tipos de combustível, potência etc.). Isto é, mesmo num cenário de alta precisão, não se prescinde da análise circunstanciada de vários modelos de simulação, cuja utilidade vai depender da sua capacidade de prever resultados satisfatórios diante da situação concreta (OSTROM, 2005, p. 117).

Enfim, a ideia de um elemento arbitrário (ou melhor, de um elemento não refutável cientificamente) na construção do conceito de eficiência ainda persiste. Afinal de contas, não existe um método a priori que diga, a partir de um dado paradigma, qual conduta seria necessariamente eficiente a partir de um determinado conjunto de fatos. Aliás, sequer temos métodos que permitam uma comparação interpessoal de utilidades numa dada comunidade, seja para a mensuração das preferências em si, seja para a comparação propriamente dita das preferências entre as pessoas que façam parte do agrupamento.

Feita essa brevíssima exposição sobre o âmbito da eficiência fora da economia e do plano ético, passamos ao estudo de como o conceito de eficiência evoluiu no pensamento econômico $^{13}$.

\section{O PROCESSO INDUSTRIAL E OS RECURSOS HUMANOS: A EFICIENCIA DO PLANO POSITIVO AO PLANO NORMATIVO}

Inicialmente, é importante ressaltar um aspecto simbólico da Escola de Salamanca no estudo da eficiência, ainda que a sua preocupação inicial tenha se voltado mais para o estudo das finanças públicas do que para processos produtivos isoladamente considerados. Pelo que

\footnotetext{
${ }^{13}$ Sem prejuízo do recorte temporal traçado no início do presente trabalho.
} 
foi visto acima, tal escola se volta contra a tradição escolástica de quase quinhentos anos e afirma uma posição no sentido de que não há como se fechar os olhos para a maneira pela qual o Estado ${ }^{14}$ conduz sua vida financeira e no sentido de que ele não deveria adotar, como regra, a intervenção no sistema econômico. É dizer: no plano acadêmico, a ideia de limitação do funcionamento do sistema político e do poder estatal (com a consequente abertura para que outros espaços da sociedade civil pudessem funcionar por suas lógicas próprias), mesmo que de forma bem incipiente, vai ter início aqui (BÖCKENFORDE, 2012, p. 455). Diante disso, é a partir desse cenário que terá início, também, a perspectiva de um conceito de eficiência para permear as relações humanas, fora do dogmatismo e do domínio secular até então exercido pela igreja. É importante destacar que a Coroa Espanhola, ainda no Século XVI, veio à falência sucessivas vezes, tendo sido marcada por eventos de fome generalizada, diminuição de capital humano (especialmente na agricultura) decorrente de expurgos de minorias, onde tal desenvolvimento acadêmico não evitou que a Espanha se tornasse um excelente exemplo dos resultados e consequências das falhas em se desenvolver organizações e instituições políticas e econômicas minimamente satisfatórias (NORTH; THOMAS, 1973, p. 123-131).

Isso colocado, neste tópico, será visto que a introdução do conceito de eficiência no plano ético se deu, inicialmente para o mero plano da análise (isto é, no plano positivo), sendo depois incorporada ao plano normativo, a partir do qual estabelece prescrições para a conduta humana.

Geralmente, esperamos que os dirigentes e gerentes de uma empresa tenham uma expectativa de que os seus agentes (notadamente, os seus empregados) entreguem o máximo de output de trabalho por unidade monetária investida na forma de remuneração. Essa constatação se torna mais perceptível nos processos modernos de produção industrial. Mesmo nas corporações de ofício da idade média, também era de se esperar que os artífices entregassem aquilo que lhes foi solicitado e que os senhores feudais fossem capazes de fornecer alguma eficiência na proteção de seus feudos contra inimigos externos.

Mas é no plano da ética que encontramos a novidade da segunda revolução social em relação ao lapso temporal de dez mil anos que vai do início do período neolítico até os fins do séc. XVIII.

\footnotetext{
${ }^{14}$ Ou qualquer que seja a instituição que lhe faça as vezes, uma vez que o conceito moderno de soberania, com a caracterização dos elementos do Estado Moderno só vai ter início com a paz da Vestfália de 1648.
} 
Aqui, a maximização da utilidade individual torna-se não apenas um meio, mas um valor em si mesmo. Nesse cenário, procura-se justificar essa matriz a partir de formulações teóricocientíficas, ainda que seja questionável a transposição imediata da eficiência nos processos de produção para a eficiência no plano das ações humanas.

Aliás, Leon Walras (1909), que formulou a teoria econômica da utilidade marginal, defendeu, em trabalho seu, ideia no sentido de que conceitos como o de utilidade e o de escassez poderiam ser estudados à luz de leis matemáticas, da mesma forma que as leis da física, onde a economia seria, também, uma ciência matemática, assim como a mecânica e astronomia.

Todavia, essa vertente de pensamento que procura alinhar a explicação do comportamento humano às leis da física newtoniana não passou imune a críticas. No dizer de Hunt e Lautzenheisser (2013, p. 239), comentando precisamente o pensamento de Walras, não há evidência empírica de que essas formulações matemáticas reflitam, com exatidão, as formas pelas quais as pessoas pensam.

De qualquer forma, fica bem emoldurado como se deu a transposição do conceito de eficiência das ciências da natureza no plano teórico para o plano da ação prática. Podemos ver que Walras procurou dotar a ciência econômica, que ainda estava em processo de amadurecimento (e talvez ainda esteja atualmente) enquanto ramo do conhecimento, dos mesmos atributos da física e da astronomia, especialmente no que se refere aos seus conceitos elementares, como "oferta", “demanda", “utilidade”, “escassez", "racionalidade”, dentre outros.

Ainda nos resta estudar sobre como se deu esse salto do plano positivo (isto é, do mero estudo teórico das relações de causalidade) para o normativo, onde a ação individual para a maximização de utilidade (numa postura hedonista, por assim dizer) torna-se um imperativo moral a ser seguido, norteando as condutas e decisões a serem tomadas.

Como vimos anteriormente, a incorporação do conceito de eficiência para o plano da ação humana é algo relativamente recente, datado de fins do século XIX e início do século XX. Mesmo Adam Smith tomava, como ponto de partida, uma aplicação da ideia de eficiência voltada apenas a processos artesanais, no sentido de transformar o ambiente natural de uma forma que seja mais conveniente ao interessado (HUNT; LAUTZENHEISSER, 2013, p. 41).

$\mathrm{Na}$ organização industrial, a introdução de um conceito normativo de eficiência elaborado com a finalidade de estabelecer um código de condutas a ser seguido pelas pessoas 
- vai se dar de forma mais evidente com o taylorismo, linha de pensamento desenvolvida por Frederick Taylor, dentre outros. O taylorismo visava aumentar a produtividade no nível operacional da atividade industrial a partir de critérios racionais aplicados aos recursos humanos respectivos. A ideia é aplicar o conceito de eficiência para que o trabalhador gere o máximo de output com um mínimo de input, numa situação em que a própria modificação dos aspectos de caráter dos envolvidos também fazia parte do processo.

Segundo o próprio Taylor (1990, p. 100), a ideia é fazer com que cada trabalhador seja sistematicamente treinado para obter o máximo de resultado com o mínimo de inputs, com mais resultado do que formas alternativas de administração de recursos humanos.

Como podemos ver, a eficiência deixa de ser algo voltado para o plano externo ao indivíduo no sentido de obter o máximo de resultados sobre os objetos em que recai o seu trabalho para se tornar um imperativo a governar a sua cosmologia e, inevitavelmente, as suas relações interpessoais.

A ideia de se implementar um aumento da produtividade mediante a atribuição individual de responsabilidades no processo produtivo não é algo errado em si mesmo. No entanto, é inevitável realizar uma observação no sentido de que, a depender do discurso produzido, essa eficiência criadora de "egoístas racionais frios e calculistas" voltados apenas ao resultado do processo, no limite, seria o reconhecimento de que a sociedade moderna (incluídas, aqui, as instituições jurídicas) seria composta de sociopatas. Não é ignorado, por outro lado, que muitas empresas não teriam condições de sobreviver no mercado e nem de inovar se fossem dirigidas por pessoas extremamente prudentes e cautelosas (LANGEVOORT, 2000. p. 148-153). Apesar de tudo isso, embora seja verdadeiro (e até necessário em certas ocasiões) que muitas pessoas ajam dessa forma, é igualmente verdadeiro que um grande número de experimentos evidencia que nem todas as pessoas são assim e que, em inúmeros casos, a cooperação é muito mais viabilizada por atendimento a considerações de reciprocidade entre os agentes envolvidos do que por imposições verticais do tipo "comando e controle". Conforme Ostrom, (2005, p. 95-96), em vários experimentos controlados (isto é, em ambientes simulados de interações entre indivíduos no papel de agentes econômicos), verifica-se uma maior tendência à cooperação voluntária no que tange à exploração de recursos comuns ${ }^{15}$ quando os

\footnotetext{
${ }^{15}$ Em tempo, conforme Mankiw (2008, p. 224-236), recursos comuns, são os bens não excludentes - onde qualquer pessoa pode usufruí-los sem conseguir excluir terceiros - e rivais - onde o uso e a fruição de uma unidade desse recurso implica uma diminuição da quantidade disponível para os demais interessados. Um exemplo comum são
} 
agentes regulados participam do processo de estabelecimento das regras mediante trocas de comunicação do que pela imposição de regras decorrente de atuação vertical de agente encarregado para elaboração de normas no método do tradicional comando-e-controle.

Assim, e diante do raciocínio ora desenvolvido, é importante perceber que atribuir a característica de "eficiente" a algo ou a alguém pode constituir-se numa predicação que é passível de uma diversidade de interpretações. Isso nos remete a uma segunda questão (a ser desenvolvida em outro trabalho): saber em que situações a resposta a tal questionamento conduzirá a uma distopia na estruturação das instituições e de incentivos a tomada de decisões das pessoas.

\section{CONCLUSÕES}

Pudemos ver, enfim, que, durante boa parte da antiguidade clássica e média, falar em eficiência nos processos de produção era algo inapropriado à luz da cosmologia dominante. A contemplação, ao mesmo tempo em que era o método dignificante da vida por excelência, não se prestava à resolução dos problemas do dia-a-dia. Lidar com a escassez era algo incompatível com tal estilo de vida.

Todavia, em situações histórica e geograficamente isoladas, conseguimos perceber o surgimento de instituições que permitiram o desenvolvimento econômico e político de sociedades, num cenário sem precedentes na história. E, aparentemente, isso ocorreu justamente em ambientes de ação "menos dignos", os quais constituíram o âmbito de operação do conceito de eficiência da antiguidade clássica - isto é, no sentido de se extrair o máximo de algo, empregando-se o mínimo de insumos.

Também foi visto que o conceito de eficiência econômica é uma construção cultural que sempre leva uma dose, em maior ou menor grau, de arbítrio, não sendo uma forma dada a priori.

Foi visto, ainda, que a incorporação de tal conceito ao plano da ética é algo relativamente recente na história da humanidade. Sendo assim, sem qualquer intuito de se esgotar o tema, um conceito de eficiência (especialmente no plano da ação intersubjetiva) tem muito mais um aspecto de uma construção cultural do que um dado a priori. Mesmo a aplicação matemática

os peixes disponíveis no mar, onde todos os pescadores competem com os demais para capturarem o máximo, o que, no limite, pode levar a uma exploração predatória de tais recursos.

Rev. de Direito, Economia e Desenvolvimento Sustentável| e-ISSN: 2526-0057| Maranhão | v. 3 | n. 2 | p. 82 - 99 | Jul/Dez. 2017. 
do conceito de eficiência a processos físicos e químicos não prescinde da necessidade de adaptação de modelos genéricos a aspectos específicos do cenário de aplicação, inclusive os de cunho cultural.

\section{REFERÊNCIAS}

ACEMOGLU, Daron; ROBINSON, James. Por que as nações fracassam: as origens do poder, da prosperidade e da pobreza. Trad. Cristiana Serra. Rio de Janeiro: Elsevier, 2012.

ALEXANDER, Jennifer. Efficiencies of Balance: Technical Efficiency, Popular Efficiency, and Arbitrary Standards in the Late Progressive Era. In: Social Studies of Science, Vol. 38, No. 3 (Jun., 2008), p. 323-334

ALI, Rabia Umar. Medieval Europe: The Myth of Dark Ages and the Impact of Islam. In: Islamic Studies, Vol. 51, No. 2, Islamabad: Islamic Research Institute, Summer 2012, pp. 155-168.

ARENDT, Hanna. A condição humana. 10. ed. Trad. Roberto Raposo. Rio de Janeiro: Forense Universitária, 2007.

ARISTÓTELES. Ética a Nicômaco. In: PESSANHA, José Américo Mota (org.). Metafísica (Livros I e II). Ética a Nicômaco. Poética. Trad. Leonel Vallandro e Gerd Bornheim. São Paulo: Abril S.A. Cultural, 1984, p. 49-236.

BÖCKENFORDE, Ernst-Wolfgang. História da Filosofia do Direito e do Estado:

Antiguidade e Idade Média. Trad. Adriana Beckman Meirelles. Porto Alegre: Sergio Antonio Fabris, 2012.

BUMSTEAD, Henry Andrews. The History of Physics. In: The Scientific Monthly. Vol. 12, n. 4. American Association for the Advancement of Science: Apr., 1921, p. 289-309.

DEMPSEY, Bernard W. Interest and Usury. Londres: Dennis Dobson Ltd., 1948.

FARIA, José Eduardo. O Direito na Economia Globalizada. São Paulo: Malheiros, 1999.

GICO Jr., Ivo. Introdução ao Direito e Economia. In: TIMM, Luciano Benetti (org.) Direito e Economia no Brasil. São Paulo: Atlas, 2012, p. 01-33.

GRICE-HUTCHINSON, Marjorie. The School of Salamanca - Readings in Spanish monetary theory. Oxford: Clarendon Press, 1952.

HAYEK, Friedrich. Direito, Legislação e Liberdade. Vol II: A miragem da justiça social. Trad. Maria Luiza X. de A. Borges. São Paulo: Visão, 1985. 
HICKS, John Richard. The Foundations of Welfare Economics. In: The Economic Journal, Vol. 49, No. 196, Dec., 1939, pp. 696-712

HOLMES, Stephen; SUNSTEIN, Cass. The cost of rights: why liberties depend on taxes. New York: W. W. Norton Company, 2000.

HOURANI, Albert. Uma história dos povos árabes. Trad. Marcos Santarrita. São Paulo: Companhia das Letras, 2006.

HUERTA DE SOTO, Jesús. The Theory of Dynamic Efficiency. Routledge: New York, 2009.

. A Escola Austríaca. 2. Ed. Trad. André Azevedo Alves. São Paulo: Instituto Ludwig von Mises Brasil, 2010.

HUNT, E. K.; LAUTZENHEISER, Mark. História do Pensamento Econômico. 3. ed. Trad. André Arruda Villela. Rio de Janeiro: Elsevier, 2013.

LANGEVOORT, Donald C. Organized Illusions: A Behavioral Theory of Why Corporations Mislead Stock Market Investors (and Cause Other Social Harms). In: SUNSTEIN, Cass (ed.). Behavioral Law and Economics. Cambridge: Cambridge University Press, 2000, p. 144-167.

MANKIW, N. Gregory. Introdução à economia. Trad. Allan Vidal Hastings. São Paulo: Cengage Learning, 2008.

NORTH, Douglass C. Structure and Change in Economic History. New York: W. W. Norton \& Company, 1981.

. Institutions, Institutional Change and Economic Performance. Cambridge: Cambridge University Press, 1990.

NORTH, Douglass C.; THOMAS, Robert Paul. The Rise of the Western World: a New Economic History. Cambridge: Cambridge University Press, 1973.

OSTROM, Elinor. Understanding Institutional Diversity. Princeton: Princeton University Press, 2005.

POSNER, Richard. Para além do direito. Trad. Evandro Ferreira e Silva. São Paulo: WMF Martins Fontes, 2009.

RAA, Thijs Ten. Efficiency Measures for Industrial Organization. In: Indian Economic Review, New Series, Vol. 45, No. 2, Performance Measurement: Methodological and Empirical Issues (July-December 2010), p. 161-192.

REALE, Giovanni; ANTISERI, Dario. História da filosofia: filosofia pagã e antiga, v. 1. Trad. Ivo Storniolo. São Paulo: Paulus, 2003.

TAYLOR, Frederick Winslow. Princípios de Administração Científica. 8. ed. Trad. Arlindo Vieira Ramos. São Paulo: Atlas, 1990. 
WALRAS, Léon. Économique et méchanique, In: Bulletin de la Societe Vaudoise de Sciences Naturelles, Vol. 45, 1909, p. 313-324.

ZERBE, Richard O. Economic Efficiency in Law and Economics. Edward Elgar: Northampton, 2001 . 